\title{
Mitochondrial DNA haplogroup study: residents of Sulaymaniyah city in the Iraqi Kurdistan Region may be genetically closer to European lineage
}

\author{
Han Nihad Mohammed Fadhl ${ }^{*}$, Shad Arif Mohammed ${ }^{2}$ and Farhad M. Abdulkarim ${ }^{3,4}$
}

\begin{abstract}
Background: Being the native inhabitants of the Neolithic Fertile Crescent, Kurds were included in several maternal lineage studies concerning the Eurasian population. However, no study was performed on the Kurdish population of Sulaymaniyah city (latitude 33.314690 and longitude 44.376759). This study was carried out on a sample of Sorani Kurds living in Sulaymaniyah for the identification of population-related single nucleotide polymorphisms (SNPs) and modes of maternal lineage.

Results: In this study, 36 randomly selected healthy unrelated Kurdish subjects were enrolled. Whole mitochondrial DNA sequencing was performed. HaploGrep 2.0 and neutrality test (Tajima's D) were employed for haplogroup identification and historical demography determination. When the outcomes were compared with previous studies in Kurds and the neighbouring nations, the identified haplogroups in the sample of study were members of the Western Eurasian haplogroups with a predominance of haplogroup $\mathrm{H}$.

Conclusions: The whole mitochondrial DNA sequence is superior to the traditional analysis of the non-coding (control) region. Our study indicates a stronger relation of the studied group to the European lineage than to their neighbouring nations.
\end{abstract}

Keywords: Whole mitochondrial DNA, Haplogroup, West Eurasia, Kurds, Sulaymaniyah city, Region of Kurdistan, Iraq

\section{Background}

After the acceptance of the Out of Africa theory, it was concluded that the long-lasting settlement of anatomically modern humans in Eurasia started 60,000-70,000 years ago in the South Western Asian corridor (Wells et al. 2004; Roostalu et al. 2007), where the descendants of haplogroup N, a branch of macro-haplogroup L3, are today's main inhabitants of West Eurasia (Richards et al. 2000; Kivisild 2015).

\footnotetext{
*Correspondence: han.muhamad@univsul.edu.iq

${ }^{1}$ Department of Basic Sciences, College of Dentistry, University

of Sulaimani, Sulaymaniyah, Iraq

Full list of author information is available at the end of the article
}

Kurds are one of today's inhabitants of West Eurasia and are the largest non-state nation in the world who speaks an Indo-European language. Even some linguists suggest an autochthonous pre-Indo-European origin of Kurds in their homeland in the Near East (Hennerbichler 2012). Furthermore, anthropology studies indicate that the forefathers of Kurds were the descendants of the first Neolithic Northern Fertile Crescent natives, who discovered the food production technologies mainly in Near East and Eurasia with the expansion of the first farmers then towards Europe (Comas et al. 2000). Cayonu, Ganj Dara and Jarmo are three archaeological sites in Kurdistan where zoological and botanical remains of agriculture and domestication were found dating back to 
8000-10,000 years before Christ (YBC) (Gallego-Llorente et al. 2016; Zarei and Rajabi-Maham 2016). Additionally, the presence of Sumerian cuneiform writing from about $3000 \mathrm{BC}$ mentioning the land of the Kurds "Land of the Kardas" is regarded as the earliest historical evidence of their existence in the area (Nasidze et al. 2005). In this regard, the land of the Kurds "Kurdistan" is located astride the Zagros Mountains of Iran, which extends to the Taurus Mountains in Turkey and to the south across the Mesopotamian Plain. Notably, Kurds remained geographically isolated and ethnically distinct despite various invasions and hostile attacks in the region (Zarei and Rajabi-Maham 2016).

Moreover, Kurds are divided into four groups, based on their language (Kurdish dialects); 1st, the northern Kurdish group (Kurmanji) spoken by the majority of Kurds in Turkey, Syria, Armenia, Azerbaijan, Georgia and parts of the Kurds in Iraq, as well as a smaller group of Kurds in Iran. Second is the Central Kurdish group (Sorani) as the majority of Kurds in Iran and Iraq. The third is the South Kurdish group (Kirmashani/Faili/Kalhuri) which is spoken by part of Kurds in Iraq and Iran. Finally, the fourth group is Zazaki, spoken only by a smaller group in Turkey (Sheyholislami 2015).

Genetic data regarding the origin of Kurds are very limited and almost all are depending on hypervariable region sequencing merely. Furthermore, in most of the previously performed studies, Kurds were taken as collateral groups with other major population studies in the region. Surprisingly, all the previous maternal lineage studies showed a closer relation of Kurds (haplogroups) to the European descent rather than to the Middle East lineage (Comas et al. 2000; Richards et al. 2000; Wells et al. 2004). Traditionally, population studies used the non-coding (control) region for mitochondrial DNA sequence analysis. This region has been shown to have less aggregation of SNPs (Lan et al. 2019) and a higher rate of mutations (Kivisild 2015). Therefore, whole mitochondrial DNA sequencing gives more accurate results and a better initial assignment of haplogroups (van Oven and Kayser 2009). To the best of our knowledge, the current study is the first one performed on a sample of Sorani Kurds from Sulaymaniyah city, to identify variance of the maternal lineage, using the whole mitochondrial DNA sequence instead of the traditionally used non-coding (control) region.

\section{Methods \\ Sampling}

This study was approved by the Ethical Committee of the Faculty of Medical Sciences/University of (BLINDED FOR PEER REVIEW) (Number 44), and verbal consents were obtained from participants. A total of 36 blood samples were obtained from unrelated individuals within the centre of Sulaymaniyah city; the Kurdish ancestry of them was ascertained for three generations.

\section{Mitochondrial DNA extraction, amplification and sequencing}

Whole genomic DNA was extracted according to the manufacturer's instructions, using a DNA extraction kit (GeNet Bio, Yuseong-gu, Daejeon, South Korea). The purity and concentration of the extracted DNA were determined using Biophotometer (Eppendorf/Germany). Mitochondrial genome was amplified in the form of four overlapping PCR fragments by using four forward primers and four reverse primers (Supplement Table S1).

The amplified PCR products were purified using a PCR purification kit (Norgen biotek, Schmon Parkway, Thorold, Canada), and other 19 reverse primers were used for sequencing of the amplified mtDNA fragments (Supplement Table S2)

\section{Data analysis}

The algorithm implemented in the HaploGrep 2.0 was used for the identification of haplogroups (Kloss-Brandstätter et al. 2011). Historical demography was determined by the neutrality test and Tajima's $D$ (Tajima 1989).

\section{Results}

In order to identify the haplogroup variants of the Sulaymaniyah city residents, the whole mitochondrial genome (MT-DNA) from 36 unrelated, healthy individuals were sequenced running the sequence through HaploGrep 2.0 programme and revealed eight haplogroups and sub-haplogroups (Table 1).

Western Eurasian haplogroups were the only determined groups in the studied samples, in which haplogroup $\mathrm{H}$ was the most common (41.6\%), and the second most common haplogroup was HV (19.4\%), while

Table 1 Identified haplogroups and sub-haplogroups with their percentages

\begin{tabular}{lll}
\hline Haplogroups & $\begin{array}{l}\text { Frequency of } \\
\text { occurrence }\end{array}$ & Percentage \\
\hline H & 15 & $41.6 \%(14 \% \mathrm{H}+28 \% \mathrm{H} 2 \mathrm{a})$ \\
$\mathrm{HV}$ & 7 & $19.4 \%(17 \% \mathrm{HV}+3 \% \mathrm{HV} 1)$ \\
$\mathrm{N}$ & 6 & $16.6 \%$ \\
R0 & 3 & $8.3 \%$ \\
J1 & 1 & $2.7 \%$ \\
T1a & 1 & $2.7 \%$ \\
U1a & 1 & $2.7 \%$ \\
U7 & 2 & $5.5 \%$ \\
Total & 36 & $100 \%$ \\
\hline
\end{tabular}


macro-haplogroup $\mathrm{N}$ which represents the dominant Western Eurasian haplogroups and its descendants as R0, $\mathrm{U}, \mathrm{T}$ and $\mathrm{J}$ were less common in the current study. Not to mention three haplogroups (T1a, J1 and U1a) were singletons (Table 1)

Furthermore, Tajima's $D$ value was calculated for demographic expansion determination, and it was strongly negative $(-2.155811, p<0.01)$ (Table 2$)$.

Furthermore, Tajima's $D$ value in the current study was compared with that of the Kurdish population in other studies. As shown in Table 3, Tajima's $D$ values were negative and differed from zero in all the previous studies, but with different strengths. Correspondingly, Hawrami, Kalhori, Kurmanji, Sorani and Georgian Kurds were all within the limits of the current results $[6,7]$. While in the case of Iraqi Kurds, Irani Kurds and Turkmen Kurds (Wells et al. 2004; Al-Zahery et al. 2013), the strength was less than in the current study.

\section{Discussion}

The Iraqi population consists of $75-80 \%$ Arabs and 20-25\% others (Al-rashedi et al. 2015; AlRashedi et al. 2016; Lazim et al. 2020). Each population has a unique genetic structure which is determined by the frequency of a particular sequence in a population. The frequency of variation in mtDNA D-loop regions can be a useful tool related to genetic diversity, human anthropology and forensic applications (Al-rashedi et al. 2015; AlRashedi et al. 2016).

Kurdistan involves parts of modern-day Iraq, Turkey, Iran and Syria, plus compact settlements in Georgia and

Table 2 Results from Tajima's neutrality test

\begin{tabular}{llllll}
\hline $\boldsymbol{m}$ & $\boldsymbol{s}$ & $\operatorname{Ps}(\boldsymbol{s} / \boldsymbol{n})$ & $\boldsymbol{\theta}$ & $\boldsymbol{\pi}$ & $\boldsymbol{D}$ \\
\hline 36 & 186 & 0.011228 & 0.0027108 & 0.001157 & -2.155811 \\
\hline
\end{tabular}

$m$ number of samples, $n$ total number of sites, $s$ number of segregating sites, $P_{s}$ $s / n, \theta \mathrm{Ps} / \mathrm{a} 1, \pi$ nucleotide diversity, $D$ Tajima's test statistic (Thomas 2001)
Armenia (Rund et al. 1991; Comas et al. 2000; Hassanpour and Email 2021). Kurds from Sulaymaniyah city "latitude 35.566864 and longitude 45.416107" are primarily the Central Kurdish group (Sorani), taking the northeast part of Iraq as their residence (Fig. 1) (Al-Zahery et al. 2013).

Western Eurasian haplogroups belonging to the macrohaplogroup N (Loogväli et al. 2004), were the only determined haplogroups among the studied samples, and this was consistent with the results of most of the previously performed studies on Kurds (Comas et al. 2000; Derenko et al. 2013; Zarei and Rajabi-Maham 2016).

Haplogroup $(\mathrm{H})$ which is believed to originate in SouthWestern Asia some 20,000 to 25,000 years ago (Achilli et al. 2004) was the most commonly encountered haplogroup in the current study (41.6\%). This finding was comparable to the European range (43.7\%) yet inconsistent with Near East results (25\%) (Richards et al. 2000; Achilli et al. 2004). In regard to the neighbour populations (Arab, Turk and Persian), the current results regarding haplogroup $\mathrm{H}$ were incompatible with Iraqis in general (19.9\%) and Iraqi Arabs in particular (16.9\%) (Al-Zahery et al. 2013; Azzawi and Oleiwi 2013), as well as with the Turks (20.98\%) and Persians (28.6\%) (Derenko et al. 2013; Serin et al. 2016). Among the haplogroup H, sub-haplogroup $\mathrm{H} 2$ was the commonest, which is frequently seen in Eastern Europe and the Caucasus; however, evidence suggests their spread from Western Europe (Pereira et al. 2005; Brotherton et al. 2013). Besides, the other common haplogroups, HV was observed in $19.4 \%$. Worthy to mention, $\mathrm{HV}$ is the ancestral clade of $\mathrm{H}$ and $\mathrm{V}$, originated between West and Central Asia; it reaches its highest incidence in the Iranian Plateau, Mesopotamia and South Caucasus (Shamoon-Pour et al. 2019). It is recognized as a crucial component of early human spread in Eurasia. Concerning the incidence of (HV) haplogroup among the neighbours, it is close to the prevalence in Iran (19-24\%) (De Fanti et al. 2015), while inconsistent

Table 3 Comparison of Tajima's neutrality test in Kurds in different studies

\begin{tabular}{|c|c|c|c|c|c|}
\hline Population & $N$ & $S$ & л & $D$ & Source \\
\hline Sulaymaniyah city & 36 & 186 & 0.001157 & -2.15 & Current study \\
\hline Sorani & 20 & 22 & 0.0058 & -1.92 & Zarei and Rajabi-Maham (2016) \\
\hline Hawrami & 21 & 19 & 0.0025 & -2.30 & Zarei and Rajabi-Maham (2016) \\
\hline Kalhori & 19 & 25 & 0.0071 & -2.04 & Zarei and Rajabi-Maham (2016) \\
\hline Kurmanji & 19 & 18 & 0.0052 & -2.18 & Zarei and Rajabi-Maham (2016) \\
\hline Iraqi Kurds & 15 & 18 & 0.0073 & -1.29 & Al-Zahery et al. (2013) \\
\hline Iran Kurds & 20 & 36 & & -1.57 & Quintana-Murci et al. (2004) \\
\hline Turkmanstan Kurds & 32 & 41 & & -1.32 & Quintana-Murci et al. (2004) \\
\hline Georgian Kurds & 29 & & & -2.140 & Comas et al. (2000) \\
\hline
\end{tabular}

$N$ number of samples, $S$ number of segregating sites, $\int$ nucleotide diversity, $D$ Tajima's test statistic 


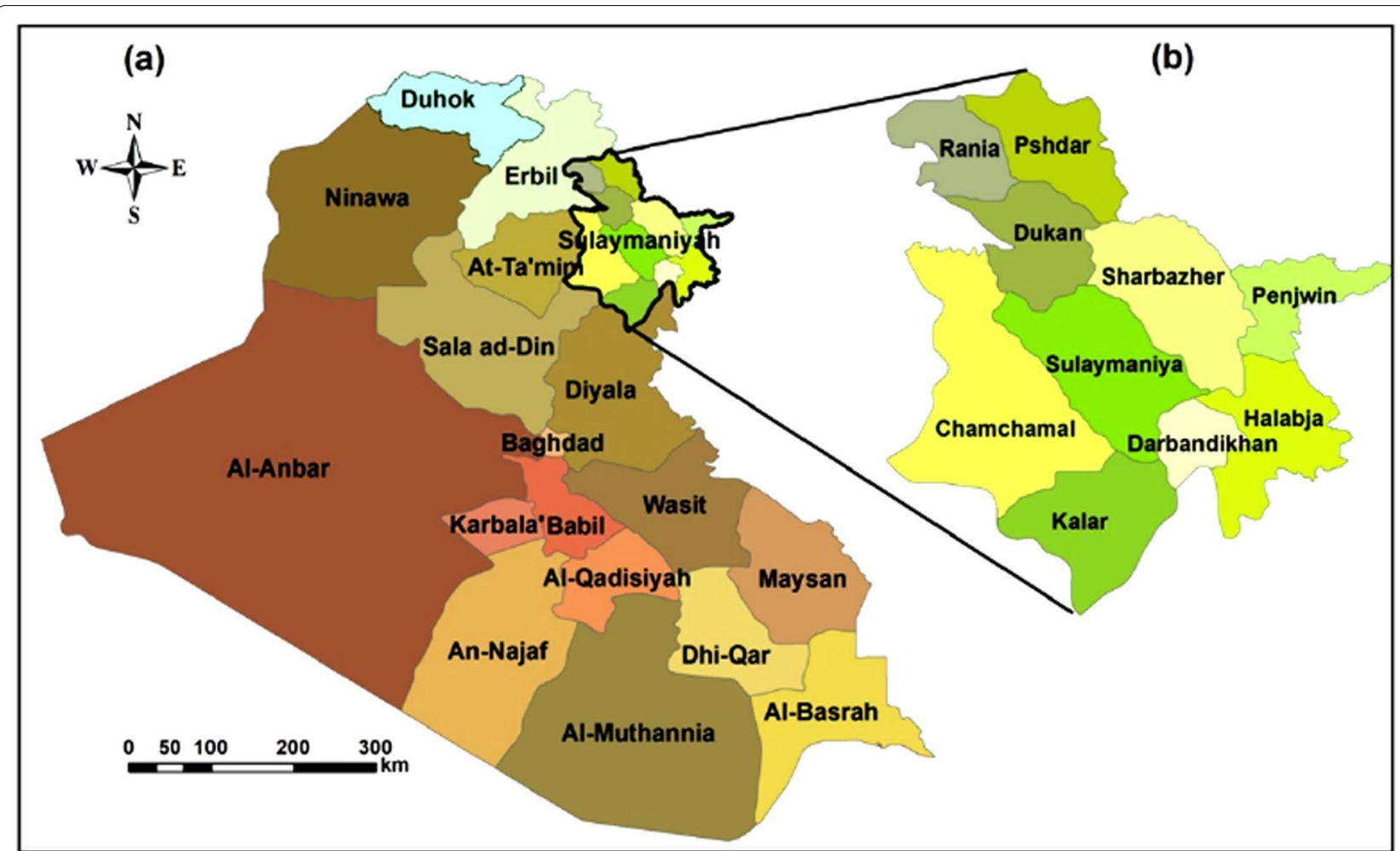

Fig. 1 Map of Sulaymaniyah city (Region of Kurdistan/lraq) (Zakaria et al. 2013)

with the incidence in the Iraqi studies (6.4\% and 10.6\%) (Al-Zahery et al. 2013; Azzawi and Oleiwi 2013) indicating a closer genetic relation of the studied sample to the Iranians than to the Iraqis. Despite that haplogroup HV is not a common haplogroup in Europe, though about $(0-10 \%)$ has been identified, distributed mainly in southern Europe (Italy and Spain) (De Fanti et al. 2015).

Furthermore, infrequent haplogroups in the current study were macro-haplogroup $\mathrm{N}$ representing the dominant Western Eurasian haplogroups (Macaulay et al. 2005), and its descendants as R0, U, T and J haplogroups. Not to mention, three haplogroups (T1a, J1 and U1a) were singletons (Table 1). Similar to previous studies (Wells et al. 2004; Zarei and Rajabi-Maham 2016), haplogroups V, $X$ and $K$ that are part of Western Eurasian haplogroups as well as Eastern Eurasian and sub-Saharan African lineage were not identified in the current study, probably because of the limited sample size. In this regard, the presence of different haplogroups, subclades and specific singletons in this study may indicate a demographic expansion of the city's population. Calculated Tajima's $D$ value as well, which was strongly negative $(-2.155811, p<0.01)$, indicates the excess of low-frequency polymorphism with a recent population size expansion in the city (demographic expansion), and as the comparison table (Table 3) shows, this result is compatible with the other previously performed studies with a minor difference in the strength with those of Iraqi Kurds, Irani Kurds and Turkman Kurds (Wells et al. 2004; $\mathrm{Al}$-Zahery et al. 2013); this may be explained by the difference in sample size, DNA sequence used and segregation sites.

Although Iraq has one of the world's oldest cultural histories and an important geographic location, forensic reference data on mitochondrial DNA control regions in Iraqi populations are scarce (Al-Zahery et al. 2003; Jabbar and Al-Rashedi 2021). Al-Zahery et al. performed analyses of mtDNA variation in 216 Iraqis and found the majority to have $\mathrm{H}, \mathrm{J}, \mathrm{T}$ and $\mathrm{U}$ haplogroups (Al-Zahery et al. 2003). To explore the genetic structure of the Iraqi population and develop a forensic database, Alden sampled 1061 individuals from the cities of Anbar, Baghdad, Basra, Diyala, Najaf and Wasit in Iraq. Analyses found that Iraq is similar to other countries in the Middle East, particularly Iran and Turkey, and is more similar to Europe than either Asia or Africa (Alden 2017). In an attempt to investigate the origin of the Basrah population (South of Iraq), Ohied and AlBadran examined the mitochondrial DNA variations by hypervariable segment 1 (HVS1) sequencing and determination of specific site haplogroups. The most widely recognized haplogroup among the Basrah population 
was $\mathrm{H}(17 \%)$, followed by $\mathrm{J}(11 \%)$ and $\mathrm{U}$ and $\mathrm{M}$ haplogroups $(9 \%)$. The values were within the range of gene diversity across the Middle East (Ohied and Al-Badran 2020).

The current study included a sample of Sulaymaniyah city residents, who belong to the Sorani group of ethnic Kurds, having a geographical and cultural contact with both Arabs of southern Iraq and Iranians in the east. Identification of various haplogroups and sub-haplogroups as well as singletons in this study indicates that the population is expanding with emerging new mutations under possible environmental and climatic changes factors (Cheng et al. 2013). Still, it is worth mentioning that the current study with its small sample size, limited by the impact of whole mitochondrial DNA sequencing, was performed at best to identify haplogroup variance in the city residents; looking forward to conducting the current procedures in a study that includes the bulk of the city residents in the near future.

\section{Conclusions}

Whole mitochondrial DNA sequencing in 36 healthy residents of Sulaymaniyah city revealed Western Eurasian 8 haplogroups dominated by $\mathrm{H}$ with a strongly negative Tajima's $D$ value indicating a closer genetic relation of the city residents to the European lineage.

\section{Abbreviations \\ DNA: Deoxyribonucleic acid; MtDNA: Mitochondrial DNA; PCR: Polymerase chain reaction; SNP: Single nucleotide polymorphisms; YBC: Years before Christ.}

\section{Supplementary Information}

The online version contains supplementary material available at https://doi. org/10.1186/s41935-021-00246-2.

Additional file 1: Table S1. Sequence of the amplification Primers of four overlapping mitochondrial DNA fragments. Table S2. Primers used for sequencing of the whole mitochondrial DNA.

\section{Acknowledgements}

We are grateful to the blood sample donors for their cooperation. We thank Mr. Dilshad Abdulla Rashid for his invaluable efforts in collecting the data.

\section{Authors' contributions}

FMA: supervision, guidance, and editing. SAM: statistical analysis. HNMF: creating the research idea and design, performing the practical work, and writing of the main text. All authors have read and approved the final manuscript.

\section{Funding}

The authors declare that they have received no funding for conducting this study.

\section{Availability of data and materials}

All data generated or analysed during this study are included in this published article.

\section{Declarations}

\section{Ethics approval and consent to participate}

This study was approved by the Ethical Committee of the Faculty of Medical Sciences/University of Sulaimani (Number 44), and verbal consents were obtained from participants.

\section{Consent for publication}

Verbal consents were taken from the study participants for publication purposes.

\section{Competing interests}

The authors declare that they have no competing interests.

\section{Author details}

1Department of Basic Sciences, College of Dentistry, University of Sulaimani, Sulaymaniyah, Iraq. ${ }^{2}$ College of Science, University of Sulaimani, Sulaymaniyah, Iraq. ${ }^{3}$ Microgene Diagnostic Canter, Harem Hospital, Sulaymaniyah, Iraq. ${ }^{4}$ Kurdistan Institute for Strategic Studies and Scientific Research (KISSR), Sulaymaniyah, Iraq.

Received: 22 June 2021 Accepted: 13 October 2021

Published online: 04 November 2021

\section{References}

Achilli A et al (2004) The molecular dissection of mtDNA haplogroup H confirms that the Franco-Cantabrian glacial refuge was a major source for the European gene pool. Am J Hum Genet 75(5):910-918. https://doi. org/10.1086/425590

Alden SD (2017) Genetic structure of the Iraqi population at 15 STRs and the consequent forensic applications (Dictoral Dissertation, University of Kansas). University of Kansas Available at: https://kuscholarworks.ku.edu/ handle/1808/27003

AlRashedi N, Jebor M, Mousa T (2016) Mitochondrial DNA markers in Arabic Iraqi population. Eur J Forensic Sci 3(3):15. https://doi.org/10.5455/ejfs. 206702

Al-rashedi NAM et al (2015) Mitochondrial DNA haplogroups observed in Iraqi population. Int J Sci Res 4(12):1424-1426. https://doi.org/10.21275/v4i12. nov151676

Al-Zahery N et al (2003) Y-chromosome and mtDNA polymorphisms in Iraq, a crossroad of the early human dispersal and of post-Neolithic migrations. Mol Phylogenet Evol 28(3):458-472. https://doi.org/10.1016/S10557903(03)00039-3

Al-Zahery N et al (2013) Characterization of mitochondrial DNA control region lineages in Iraq. Int J Legal Med 127(2):373-375. https://doi.org/10.1007/ s00414-012-0757-8

Azzawi BI, Oleiwi AA (2013) Mitochondrial genome variation within Iraqi population. Int J Sci Technol 8(3):23-27. https://doi.org/10.12816/0010067

Brotherton P et al (2013) Supplementary information - Neolithic mitochondrial haplogroup $\mathrm{H}$ genomes and the genetic origins of Europeans. Nat Commun 4;1-10

Cheng YT et al (2013) Mitochondrial DNA content contributes to climate adaptation using chinese populations as a model. PLoS One 8(11):1-7. https://doi.org/10.1371/journal.pone.0079536

Comas D et al (2000) Georgian and Kurd mtDNA sequence analysis shows a lack of correlation between languages and female genetic lineages. Am J Phys Anthropol 112(1):5-16 (https://doi.org/10.1002/ (SICI) 1096-8644(200005) 112:1<5::AID-AJPA2>3.0.CO;2-Z)

De Fanti S et al (2015) Fine dissection of human mitochondrial DNA haplogroup HV lineages reveals Paleolithic signatures from European glacial refugia. PLoS One 10(12):14-16. https://doi.org/10.1371/journal.pone. 0144391

Derenko M et al (2013) Complete mitochondrial DNA diversity in Iranians. PLoS One 8(11):1-15. https://doi.org/10.1371/journal.pone.0080673

Gallego-Llorente M et al (2016) The genetics of an early Neolithic pastoralist from the Zagros, Iran. Sci Rep 6(Cdc):1-2. https://doi.org/10.1038/srep3 1326

Hassanpour A, Email Y (2021) The Kurdish experience, pp 1-16 
Hennerbichler F (2012) The origin of Kurds. Adv Anthropol 02(02):64-79. https://doi.org/10.4236/aa.2012.22008

Jabbar SM, Al-Rashedi NAM (2021) Mitochondrial DNA control region variation in an Iraqi population sample. Int J Legal Med 135(2):421-425. https://doi. org/10.1007/s00414-020-02452-4

Kivisild T (2015) Maternal ancestry and population history from whole mitochondrial genomes. Invest Genet 6(1):1-10. https://doi.org/10.1186/ s13323-015-0022-2

Kloss-Brandstätter A et al (2011) HaploGrep: a fast and reliable algorithm for automatic classification of mitochondrial DNA haplogroups. Hum Mutat 32(1):25-32. https://doi.org/10.1002/humu.21382

Lan Q et al (2019) MtDNA polymorphism analyses in the Chinese Mongolian group: efficiency evaluation and further matrilineal genetic structure exploration. Mol Genet Genomic Med 7(10):1-14. https://doi.org/10. 1002/mgg3.934

Lazim H et al (2020) Population genetic diversity in an Iraqi population and gene flow across the Arabian Peninsula. Sci Rep 10(1):1-11. https://doi. org/10.1038/s41598-020-72283-1

Loogväli EL et al (2004) Disuniting uniformity: a pied cladistic canvas of mtDNA haplogroup H in Eurasia. Mol Biol Evol 21(11):2012-2021. https:// doi.org/10.1093/molbev/msh209

Macaulay $V$ et al (2005) Single, rapid coastal settlement of Asia revealed by analysis of complete mitochondrial genomes. Science 308(5724):10341036. https://doi.org/10.1126/science.1109792

Nasidze I et al (2005) MtDNA and Y-chromosome variation in Kurdish groups. Ann Hum Genet 69(4):401-412. https://doi.org/10.1046/j.1529-8817.2005. 00174.x

Ohied BM, Al-Badran Al (2020) Mitochondrial DNA (hypervariable region I) diversity in Basrah population - Iraq. Genomics 112(5):3560-3564 https://doi.org/10.1016/j.ygeno.2020.04.004

Pereira L et al (2005) High-resolution mtDNA evidence for the late-glacia resettlement of Europe from an Iberian refugium. Genome Res 15(1):1924. https://doi.org/10.1101/gr.3182305

Richards $\mathrm{M}$ et al (2000) Tracing european founder lineages in the near eastern mtDNA pool. Am J Hum Genet 67(5):1251-1276. https://doi.org/10.1016/ S0002-9297(07)62954-1

Roostalu $U$ et al (2007) Origin and expansion of haplogroup $H$, the dominant human mitochondrial DNA lineage in West Eurasia: the Near Eastern and
Caucasian perspective. Mol Biol Evol 24(2):436-448. https://doi.org/10. 1093/molbev/msl173

Rund D et al (1991) Evolution of a genetic disease in an ethnic isolate: $\beta$-Thalassemia in the Jews of Kurdistan. Proc Natl Acad Sci U S A 88(1):310-314. https://doi.org/10.1073/pnas.88.1.310

Serin A et al (2016) Mitochondrial DNA control region haplotype and haplogroup diversity in South Eastern Turkey. Forensic Sci Int Genet 24(Cdc):176-179. https://doi.org/10.1016/j.fsigen.2016.07.011

Shamoon-Pour M, Li M, Merriwether DA (2019) Rare human mitochondrial $\mathrm{HV}$ lineages spread from the Near East and Caucasus during post-LGM and Neolithic expansions. Sci Rep 9(1):1-29. https://doi.org/10.1038/ s41598-019-48596-1

Sheyholislami J (2015) The language varieties of the Kurds. In: THE KURDS: History, Religion, Language, Politics., (January), vol 184, pp 30-51

Tajima F (1989) Statistical method for testing the neutral mutation hypothesis by DNA polymorphism. Genetics 123(3):585-595. https://doi.org/10. 1093/genetics/123.3.585

Thomas RH (2001) Molecular evolution and phylogenetics. Heredity 86(3):385385. https://doi.org/10.1046/j.1365-2540.2001.0923a.x

van Oven M, Kayser M (2009) Updated comprehensive phylogenetic tree of global human mitochondrial DNA variation. Hum Mutat 30(2):18853457. https://doi.org/10.1002/humu.20921

Wells RS et al (2004) Where west meets east : the complex mtDNA landscape of the Southwest and Central Asian Corridor. Anatolia 74(5):827-845 Available at: http://www.pubmedcentral.nih.gov/articlerender.fcgi? artid $=1181978 \&$ tool=pmcentrez\&rendertype=abstract

Zakaria S et al (2013) Estimation of annual harvested runoff at Sulaymaniyah Governorate, Kurdistan region of Iraq. Nat Sci 05(12):1272-1283. https:// doi.org/10.4236/ns.2013.512155

Zarei F, Rajabi-Maham H (2016) Phylogeography, genetic diversity and demographic history of the Iranian Kurdish groups based on mtDNA sequences. J Genet 95(4):767-776. https://doi.org/10.1007/ s12041-016-0692-4

\section{Publisher's Note}

Springer Nature remains neutral with regard to jurisdictional claims in published maps and institutional affiliations.

\section{Submit your manuscript to a SpringerOpen ${ }^{\circ}$ journal and benefit from:}

- Convenient online submission

- Rigorous peer review

- Open access: articles freely available online

- High visibility within the field

- Retaining the copyright to your article

Submit your next manuscript at springeropen.com 